\title{
Oxytocin augmentation in grandmultiparous parturients: to give or not to give?
}

\author{
Yaakov Bentov $\cdot$ Eyal Sheiner
}

Received: 13 November 2008 / Accepted: 19 February 2009 / Published online: 11 March 2009

(C) Springer-Verlag 2009

\begin{abstract}
Objective The present editorial was aimed to determine policies toward the use of oxytocin for labor augmentation among grandmultiparous (above 5 deliveries) parturients (GMPs).

Study design A questionnaire regarding attitudes toward oxytocin augmentation during labor among GMPs was distributed to all chairpersons of Ob/Gyn departments throughout the country; 20/23 chairpersons responded to the national survey.

Results In all, 85\% (17/20) of the chairpersons allowed the use of oxytocin for augmentation of labor in GMPs. Those answering positively to this question did not choose to limit the use of oxytocin for any level of parity. Moreover, $58 \%(11 / 19)$ of them did not obligate the concurrent use of intrauterine pressure catheter while using oxytocin augmentation in these patients. Only $22 \%$ (4/18) of the medical centers surveyed limited the maximal dose of Oxytocin among GMPs. The limited dose of oxytocin ranged from 8 to $16 \mu / \mathrm{min}$. Alternatives for oxytocin augmentation in GMPs were breast stimulation (30\%), and surgical induction (15\%). Nevertheless, $50 \%$ of the chairpersons found no other suitable alternative for labor augmentation among GMPs.

Conclusion Oxytocin seems like an accepted method for labor augmentation among grandmultiparous women.
\end{abstract}

Y. Bentov $\cdot$ E. Sheiner $(\bowtie)$

Department of Obstetrics and Gynecology,

Faculty of Health Services, Soroka University Medical Center,

Ben-Gurion University of the Negev, P.O. Box 151,

84101 Beer-Sheva, Israel

e-mail: sheiner@bgu.ac.il
Moreover, the vast majority of chairpersons did not mandate additional safety measures such as internal uterine catheter or limited dose regimens in these patients.

Keywords Grand multiparity · Oxytocin ·

Labor augmentation - Uterine rupture

\section{Introduction}

Oxytocin is commonly used for labor augmentation, especially in cases where labor fails to progress according to Friedman's curve [6, 7, 12]. However, the use of oxytocin in grandmultiparous parturients (GMPs) (above 5 deliveries) as well as in patients with a scarred uterus is believed to expose them to a higher rate of peripartum complications including uterine rupture [13, 15]. Accordingly, women with high parity (above 5 deliveries) are generally not given oxytocin in the US. While several studies found grand multiparity as a risk factor for adverse perinatal outcome [5, 10], others claim that in modern obstetric practice grand multiparity per se should not be considered as a risk factor $[2,14]$. The alternative for labor augmentation in grandmultiparous with hypotonic uterine contractions (i.e., breast stimulation) is of unproved efficacy and safety. Limiting the use of oxytocin in GMPs might lead to higher rates of cesarean deliveries, due to labor dystocia [6, 12]. The present editorial was conducted in order to determine policies toward the use of oxytocin for labor augmentation among grandmultiparous patients.

A questionnaire regarding the attitude toward oxytocin augmentation of labor in GMPs was distributed to all chairpersons of Ob/Gyn Departments throughout Israel. 20 out of 23 chairpersons responded to the National Survey. 
The participants were asked the following questions:

1. Do you allow the use of oxytocin for augmentation of labor in grandmultiparous patients?

2. Is there a parity limit in using oxytocin for labor augmentation in your ward?

3. Does the use of oxytocin augmentation in these patients mandate the use of internal uterine pressure catheter (IUPC)?

4. Is the use of oxytocin dose-limited?

5. What is the maximal dose of oxytocin used in your institute?

6. What other regimens for labor augmentation are used in your institute for grandmultiparous women?

\section{Results}

In all, $85 \%(17 / 20)$ of the chairpersons allowed the use of oxytocin for augmentation of labor in GMPs. Those that use oxytocin did not limit its use according to patient's parity. Moreover, 58\% (11/19) of the chairpersons do not require an intrauterine pressure catheter (IUPC) to be installed while using oxytocin augmentation in these patients. We did not find a correlation between the rate of GMP deliveries and the center's recommendation regarding the use of IUPC. Only 22\% (4/18) of the Medical Centers surveyed limited the maximal dose of oxytocin among grandmultiparous women (range: 8-16 mu/min). Alternatives for oxytocin augmentation in GMPs were breast stimulation (30\%), and surgical induction by artificial rupture of membranes $(15 \%)$. Nevertheless, $50 \%$ of the chairpersons stated that there is no other suitable alternative for labor augmentation except oxytocin even in grandmultiparous women.

\section{Discussion}

The present study found that in spite of the textbook recommendation [4], there is a national consensus regarding the use of oxytocin for augmentation of labor in grandmultiparas. It is noteworthy that in several institutions in Israel, the prevalence of grand multiparity is as high as $20 \%$ [3, 6, 8]. Avoiding the use of oxytocin could lead to a marked increase in the rate of Cesarean deliveries. Although the cesarean mode of delivery seems to be a relatively safe procedure with a certain outcome, one should keep in mind that anesthesia and laparotomy increases the risk for maternal morbidity [9].

Awais and Lebherz [1] described uterine rupture subsequent to the use of oxytocin for labor augmentation in high parous women. Vedat et al. [15] reviewed 150 cases of uterine rupture in late pregnancy that occurred over an 8-year period. 114 uterine ruptures (76\%) occurred in previously scarred uteri. Other common etiological factors in this study for uterine rupture were grandmultiparity, cephalopelvic disproportion, fetal malpresentation, and oxytocin stimulation of labor.

Ofir et al. [11] analyzed 42 cases of uterine rupture took place between the years 1989 and 1999 at the delivery room of the Soroka University Medical Center. A multivariable analysis revealed three independent risk factors for uterine rupture: previous cesarean delivery, malpresentation and failure to progress during the second stage of labor. Oxytocin augmentation and grandmultiparity were not found as independent risk factors for uterine rupture in our groups' study. Likewise, Laor et al. [8] prospectively evaluated 130 consecutive low risk grandmultiparous women receiving oxytocin during delivery. No maternal or perinatal adverse effects were detected. While investigating risk factors for emergency peripartum hysterectomy (which was mainly due to uterine rupture), grandmultiparity was found to be an independent risk factor (odds-ratio $=3.4,95 \%$ confidence interval 1.8-6.3). However, these patients had lower rates of labor induction and/or augmentation with oxytocin as compared to the controls [11]. Moreover, Ben-Aroya et al. [3] reviewed 11,075 deliveries of GMPs. 424 (3.8\%) of them received oxytocin augmentation. No significant differences were found between the oxytocin and the control groups in the rates of uterine rupture. Also, no significant differences were found between the oxytocin and the control groups in the rates of placental abruption, intrapartum fetal death, postpartum hemorrhage, fetal distress, meconium-stained amniotic fluid, an Apgar score of less than 7 at $5 \mathrm{~min}$, Cesarean section, retained placenta and vaginal and cervical lacerations. The authors concluded that the use of oxytocin in the GMP was a safe procedure with no significant increase in peripartum complications.

In concordance with the recent studies, we conclude that oxytocin is an accepted method for labor augmentation among grandmultiparous women. Moreover, in the present survey, the vast majority of chairpersons did not mandate additional safety measures such as internal uterine catheter or limited dose regimens among these patients.

Conflict of interest statement None.

\section{References}

1. Awais GM, Lebherz TB (1970) Ruptured uterus. A complication of oxytocin induction and high parity. Obstet Gynecol 36:465-472

2. Babinszki A, Kerenyi T, Torok O, Grazi V, Lapinski RH, Berkowitz RL (1999) Perinatal outcome in grand and great-grand multiparity: effects of parity on obstetric risk factors. Am J Obstet Gynecol 181:669-674. doi:10.1016/S0002-9378(99)70511-9

3. Ben-Aroya Z, Yochai D, Silberstein T, Friger M, Hallak M, Katz M, Mazor M (2001) Oxytocin use in grand-multiparous patients: 
safety and complications. J Matern Fetal Med 10:328-331. doi: $10.1080 / 714904358$

4. Cunningham FG, Gant NF, Leveno KJ, Gilstrap LC III, Hauth JC, Wenstrom KD Williams (2001) Obstetrics, 21st edn. McGrawHill, New York, pp 646-647

5. Evaldson GR (1990) The grand multipara in modern obstetrics. Gynecol Obstet Invest 30:217-223

6. Feinstein U, Sheiner E, Levy A, Hallak M, Mazor M (2002) Risk factors for arrest of descent during the second stage of labor. Int J Gynaecol Obstet 77:7-14. doi:10.1016/S0020-7292(02)00007-3

7. Friedman EA (1954) The graphic analysis of labor. Am J Obstet Gynecol 68:1568-1575

8. Laor D, Seidman DS, Yaffe H, Voss E, Diamant YZ, Gale R (1989) A prospective study of the active management of labor in women of high parity. Eur J Obstet Gynecol Reprod Biol 30:111115. doi:10.1016/0028-2243(89)90056-7

9. Lydon-Rochelle M, Holt VL, Martin DP, Easterling TR (2000) Association between method of delivery and maternal re hospitalization. JAMA 283:2411-2416. doi:10.1001/jama.283. 18.2411
10. Maymon E, Ghezzi F, Shoham-Vardi I, Hershkowitz R, Franchi M, Katz M, Mazor M (1998) Peripartum complications in grand multiparous women: para 6-9 versus para $>$ or $=10$. Eur J Obstet Gynecol Reprod Biol 81-1:21-25

11. Ofir K, Sheiner E, Levy A, Katz M, Mazor M (2003) Uterine rupture-risk factors and pregnancy outcome. Am J Obstet Gynecol 189:1042-1046. doi:10.1067/S0002-9378(03)01052-4

12. Sheiner E, Levy A, Feinstein U, Hallak M, Mazor M (2002) Risk factors and outcome of failure to progress during the first stage of labor: a population-based study. Acta Obstet Gynecol Scand 81:222-226. doi:10.1034/j.1600-0412.2002.810306.x

13. Sheiner E, Levy A, Katz M, Mazor M (2003) Identifying risk factors for peripartum cesarean hysterectomy. A population-based study. J Reprod Med 48:622-626

14. Toohey JS, Keegan KA Jr, Morgan MA, Francis J, Task S, deVeciana M (1995) The "dangerous multipara": fact or fiction? Am J Obstet Gynecol 172:683-686. doi:10.1016/0002-9378(95) 90593-6

15. Vedat A, Hasan B, Ismail A (1993) Rupture of the uterus in labor: a review of 150 cases. Isr J Med Sci 29:639-643 